Issue $3 / 2017$

\title{
THE PUBLIC PURCHASES IN ROMANIA, A GEOPOLITICAL DYNAMIC OF YESTERDAY AND TODAY ENVIRONMENT
}

\author{
Ionuț Cristian NUTA ${ }^{1}$ \\ ${ }^{1}$ Spiru Haret University, Faculty of Economic Sciences, Fabricii Street, no. 46G, \\ Bucharest, 030045, Romania, Tel.: +40212169793, Fax:+40213169793, \\ Email:i0nutz22@yahoo.com
}

\begin{abstract}
This paper intends to briefly explain how the internal regulations concerning the Romanian public purchases have changed lately.
\end{abstract}

Keywords: public purchases; transposition of the European Union laws into national laws.

JEL Classification: $\mathrm{H}_{3}, \mathrm{H}_{4}$

\section{Introduction}

Ten years ago, in January 2007, Romania entered the European Union family. That process called for some immediate changes and continuously up-dates in the internal regulations in many economic areas, including the public purchases in Romania.

\section{The Legal System}

As significant change on the internal regulations and processes on the public purchases, Romania had to do the transposition of the E.U. laws into national laws.

Among the first steps taken, the institution subordinated to the Romanian Government, named 'National Authority for Regulating and Monitoring the Public Procurement' (briefly called NARMP), together with the General Secretariat of the Government, submitted for approval to the Government, according to the Emergency Ordinance (G.E.O) no. 34/2006.

Prior the harmonization of the local laws to the E.U. legislation, the public contracts were in effect following the national legal documents, such as G.E.O. 34/2006. There might have existed some discrepancies between the local and the E.U. Directives. 

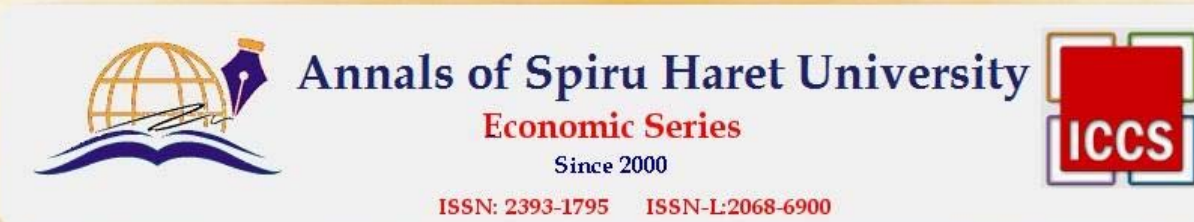

Issue $3 / 2017$

Diagram 1: Interpretation of public procurement on complex or high-risk projects

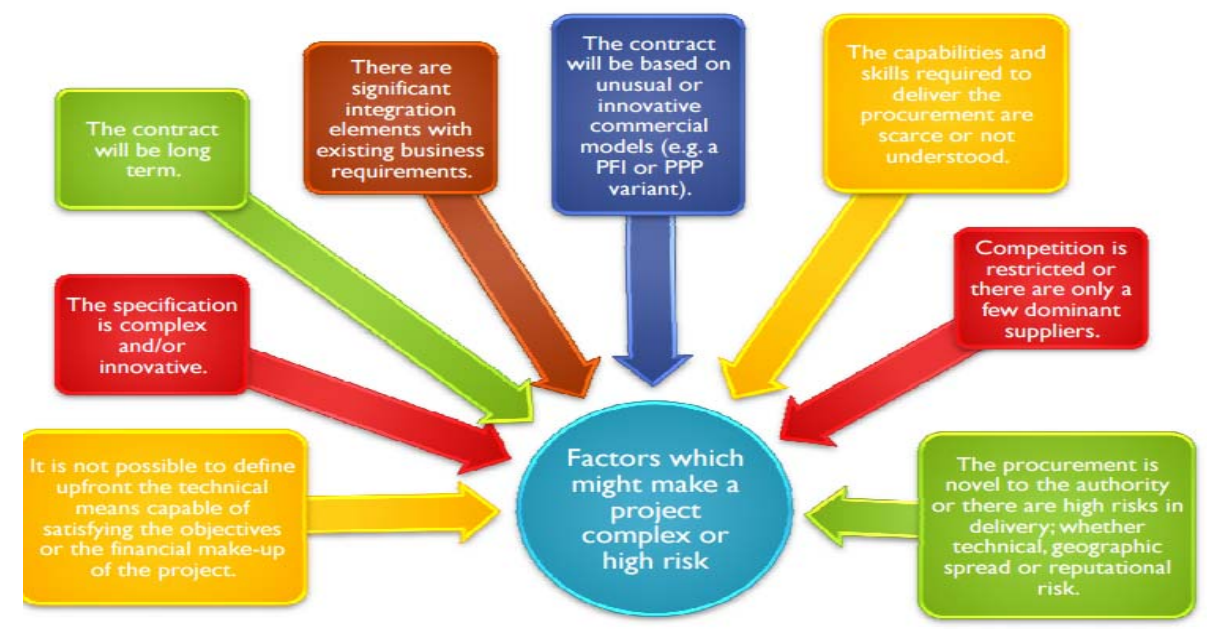

Source:

http://m.amcham.ro/UserFiles/seminarPaper/AMCHAM\%20public\%20procurement\%20R OMANIA\%2025\%20Iunie_08221328.pdf

\section{National Regulations for the Purchases with Values below the EU's Normative}

Since the very beginning a mention has to be made: according to the national rules, the purchases had to follow different ways to be fulfilled, depending on their value. Thus, for the contracts of which value was defined between reference 1 and reference 2 defined as Medium Contracts, the awarding procedures and conditions for their application was identical to those contracts named Large contracts, with few exceptions. Once a contract published, the award notices shall be binding only at national level and the period provided for preparing and submitting the offers are lower while the 'waiting' period was only 4 days.

The value of Small Contracts, contained between reference 2 and reference 3, the award procedure was applied without additional conditions in the request for tenders.

After transposition of the E.U. laws into national laws, the procurement of services and public acquisitions is the subject of EU Directives 2004/18/EC and 2004/17/EC and they have to be followed as Romania became part of the E.U. 


\section{Annals of Spiru Haret University \\ Economic Series \\ Since 2000 \\ ISSN: 2393-1795 ISSN-L:2068-6900}

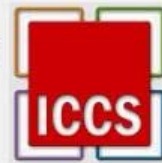

Issue $3 / 2017$

In case of contracts in the sectors of water, energy, transport, postal services or other relevant activities, as defined by the Sectorial Law, a public procurement contract is usually awarded pursuant to an open, or limited public tender, or competitive negotiation, or competitive dialogue. In these sectors, the other abovementioned procedures can be used by the contracting authorities when awarding a public procurement contract only under the specific circumstances provided by the sectorial law.

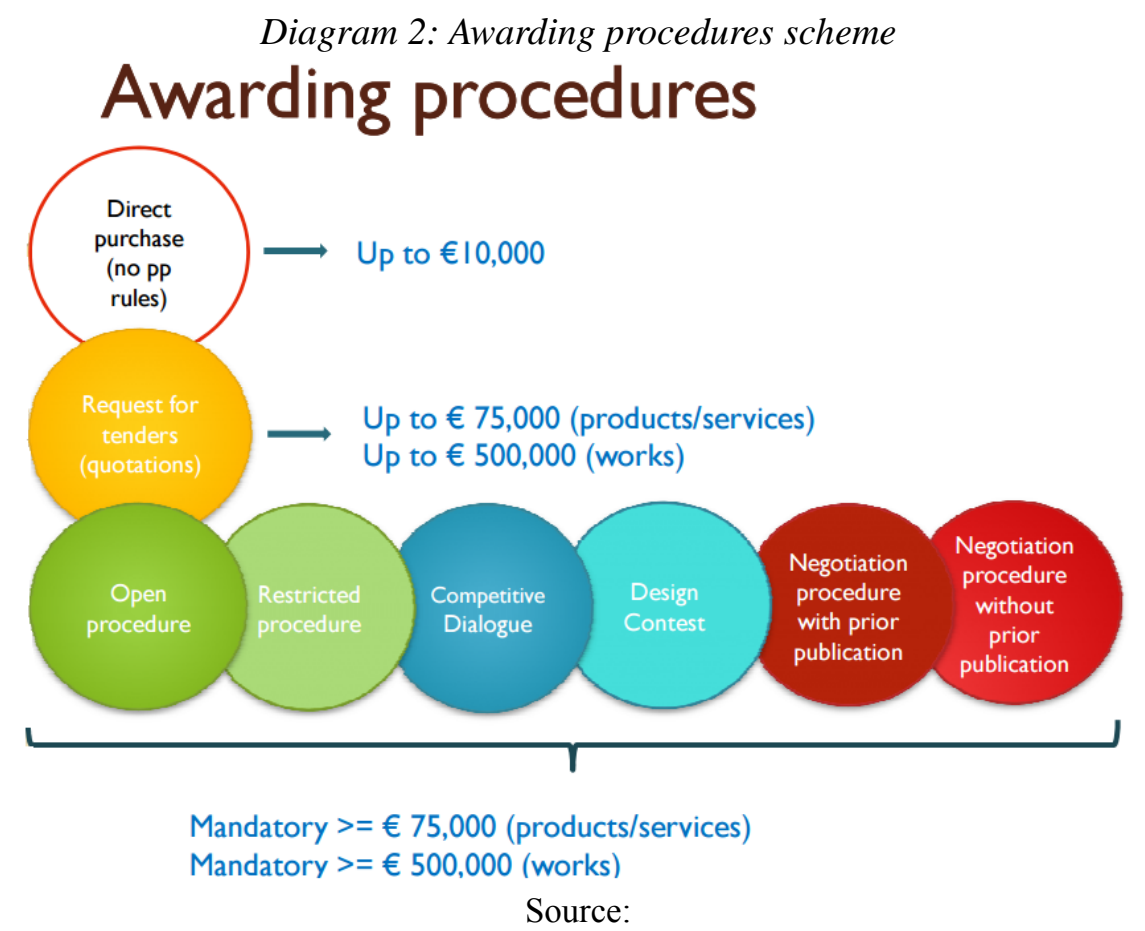

http://m.amcham.ro/UserFiles/seminarPaper/AMCHAM\%20public\%20procurement\%20R OMANIA\%2025\%20Iunie_08221328.pdf

For large purchases projects, the regular procedure is usually inflexible as it allows just limited talking with bidders.

Therefore, the authorities should ideally follow the competitive dialogue procedure - do otherwise if there are exceptional circumstances that would justify the negotiated procedure. 

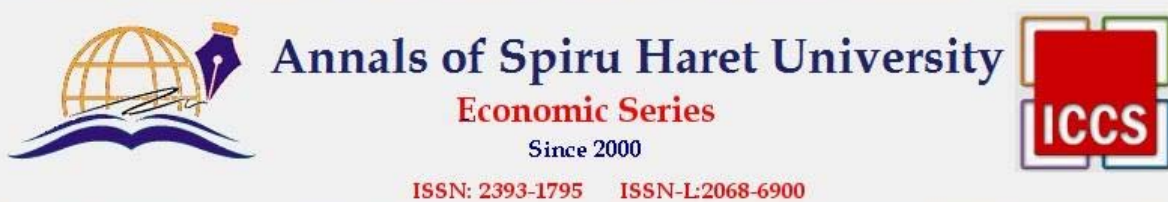

Issue $3 / 2017$

The competitive dialogue procedure is a flexible procedure, fitting where there is a need for authorities to talks about the aspects of proposed deal with competitors.

Diagram 3: Steps of competitive dialogue scheme

Contract

award

Competitive dialogue

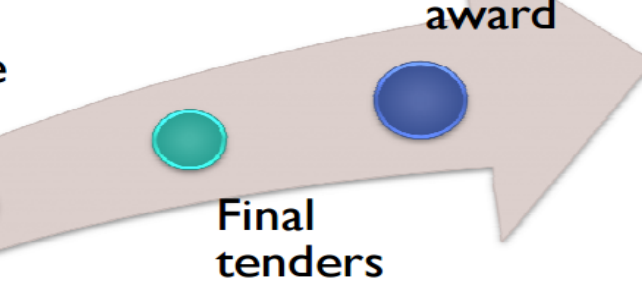

\section{Pre-Qualification \\ \& Selection}

\section{Preparation}

Source:

http://m.amcham.ro/UserFiles/seminarPaper/AMCHAM\%20public\%20procurement\%20R OMANIA\%2025\%20Iunie_08221328.pdf

For example, the procedure would be used where authorities cannot define clearly in advance the technical means capable of satisfying their needs or objectives, or where there is a range of options for the legal and/or financial structure of a Project.

Under competitive dialogue, a similar pre-selection procedure is undertaken to that used for the restricted procedure.

Shortlisted parties are then invited to participate in dialogue, which may have several stages. This helps to refine the requirement through supplier input and gives the opportunity for meaningful negotiations. Once this stage is concluded, suppliers are invited to submit a final tender.

There is only one provision for the contracting authority to ask bidders to "clarify, specify and fine-tune" their final bids before a preferred bidder is chosen.

\section{The Main Institutions of This Public Purchases System}

National Authority for Regulating and Monitoring the Public Procurement' (or briefly called NARMP) is the public entity under the command of Romanian Government. 

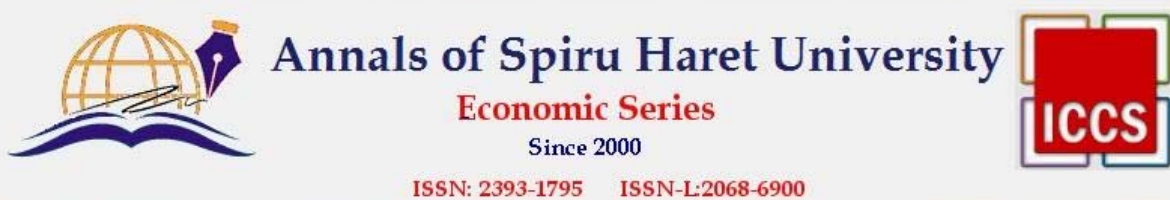

Issue $3 / 2017$

NARMP's roles include - but not limited to - of elaboration and deployment of the purchasing policies for the public sector:

$\checkmark$ creates the legislation environment;

$\checkmark$ defines the appropriate norms for applying the laws in the daily activities;

$\checkmark$ works together with other Departments or Directions under the command of Romanian Government to obtain the best ways for putting the regulations in practice;

$\checkmark$ monitors, evaluates and is over viewing the process of public acquisitions.

The body for coordination and verify of public purchases, briefly called UCVPP, is the special unit under the Romanian Government which verifies the procedures related to the processes of awarding the contracts that submits to the provisions for the public purchases during initial period and ending with the award of the contracts.

\section{Central Purchase Directories}

The aim is to create a central body which shall be handling the awarding of public deals/agreements for the public administration (has been raised a proposition for a law in this direction). Anyhow, there are few departments or entities that are doing purchases for their institutions under their command (ex. the Ministry of Health purchases medications or devices for the public Medicine Centres).

\section{The Supervise entities in Romania are:}

$\checkmark$ The Court of Accounts, which is the supreme unit in auditing the spent of public funds; and

- The Romanian Audits Authority is the operational department connected to the Court of Accounts and the other institutions handling the management of not reimbursable public money.

The Romanian Reviewing Authorities refer to either the administrative side of solution or the legal one. From the administration perspective - the National Council of Solving the Complains which is an independent structure that solves in average about five thousands complains twelve months. The deadline to solve complains is limited to 30 days.

From the justice point of view, there are several bodies, such as: the tribunal of each Romanian county, the Appeal Court, of each Romanian sub-region or region, and the Bucharest Main Appeal Court. 
Issue $3 / 2017$

Diagram 4: Scheme of Public procurement system administrative institutions

\section{Public procurement system administrative institutions}

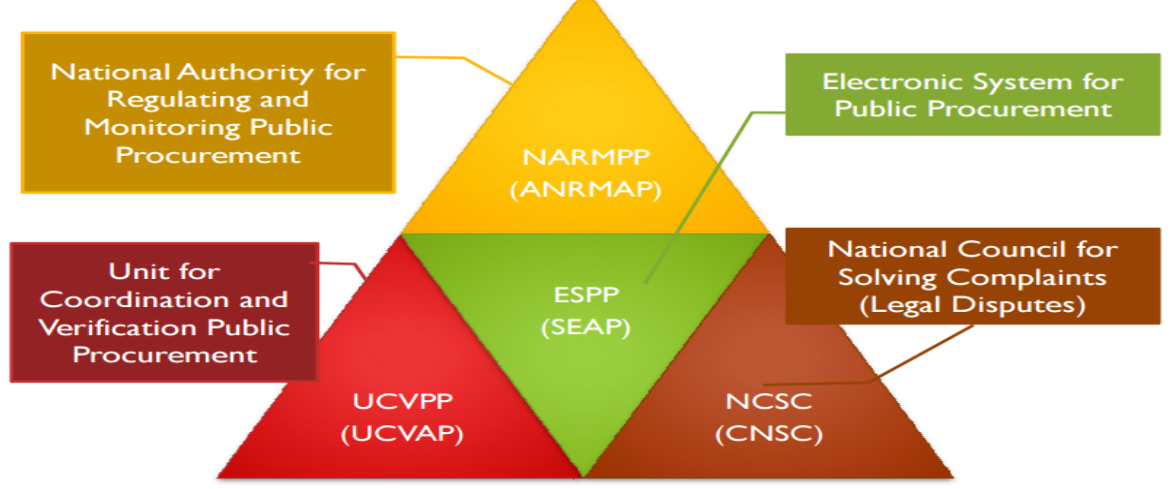

Source:

http://m.amcham.ro/UserFiles/seminarPaper/AMCHAM\%20public\%20procurement\%20R OMANIA\%2025\%20Iunie_08221328.pdf

The alternative way of the above-detailed procedure is to use:

1. Framework agreement

A framework agreement as an agreement with suppliers, the purpose of which is to establish the terms governing contracts to be awarded during a given period, in particular with regard to price and quantity. In other words, a framework agreement is a general term for agreements with providers which set out terms and conditions made throughout the term of the agreement. The framework agreement may, itself, be a contract to which the EU procurement rules apply.

\section{Dynamic purchases system}

A 'dynamic purchases system' is an entirely electronic process for making commonly used acquisitions, the characteristics of which meet the requirements of the contracting authority, which is limited in duration and open throughout its validity to any economic operator which satisfies the selection criteria and has submitted an indicative tender that complies with the specification.

In order to set up a dynamic purchasing system, contracting bodies shall follow the rules of the open procedure in all its phases up to the award of the contracts to be concluded under this system. 


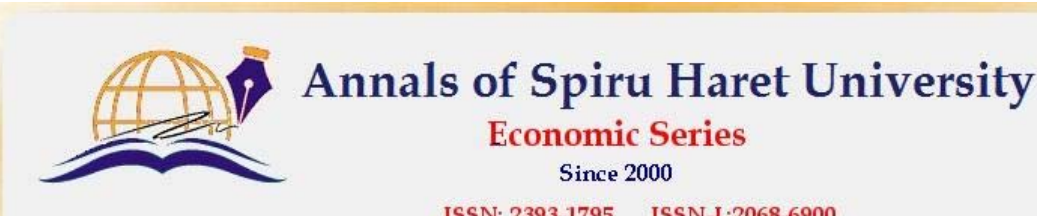

ISSN: 2393-1795 ISSN-I -2068-6900

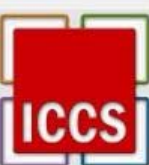

Issue $3 / 2017$

To be admitted to the system, all the participants in the auctions need to fulfil the selection criteria and to have submitted an indicative tender which complies with the specification including all the possible necessary additional documents.

\section{Electronic auctions}

An 'electronic auction' is a repetitive process involving an electronic device for the presentation of new prices, revised downwards, and/or new values concerning certain elements of tenders, which occurs after an initial full evaluation of the tenders, enabling them to be ranked using automatic evaluation methods. In open, restricted or negotiated procedures the contracting authorities may decide that the award of a public contract shall be preceded by an electronic auction when the contract specifications can be established with precision. In the same circumstances, an electronic auction may be held on the reopening of competition among the parties to a framework agreement and on the opening for competition of contracts to be awarded under the dynamic purchasing system.

Public acquisition procedures might be complicated. And corruption can occur at any stage of the public acquisition process, unless not controlled very well by defined rules and laws.

Transposition of the new European Directives in Romania has increased the transparency of the public purchases system of our country, so the corruption of the system has gone to the lowest level possible.

Also, it has engaged the Government of Romania and all relevant stakeholders with the scope of driving improvements in the public procurement which are included in the public procurement strategies.

\section{References:}

1. AmCham (2008), Public Procurement in Romania, http://m.amcham.ro/UserFiles/ seminarPaper/AMCHAM\%20public\%20procurement\%20ROMANIA\%2025\%20Iun ie 08221328.pdf

2. Authority for the Supervision of Public Contracts - Department for the Co-ordination of European Union Policies, The Comparative Survey on the National Public Procurement Systems across the PPN http://www.publicprocurementnetwork.org/ docs/ItalianPresidency/Comparative\%20survey\%20on\%20PP\%20systems\%20across $\% 20 \mathrm{PPN} . \mathrm{pdf}$ )

3. http://www.buzescu.com/romanian-public-procurement-laws/ 

CASE STUDY 
